\title{
Benefits from 4th Year Surgical Course for Medical Students upon Reaching 6th Year Surgical Course at the Faculty of Medicine, Umm Al-Qura University
}

\author{
Hatem A. Sembawa ${ }^{1}$ \\ ${ }^{1}$ Faculty of Medicine, Umm Al-Qura University, Saudi Arabia \\ Correspondence: Hatem A. Sembawa, Assistant professor of general surgery in the surgical department at \\ Faculty of Medicine, Umm Al-Qura University, Saudi Arabia. E-mail: hasembawa@uqu.edu.sa
}

Received: December 17, 2018

Accepted: March 3, 2019 Online Published: May 20, 2019

doi:10.5539/jel.v8n3p180

URL: https://doi.org/10.5539/jel.v8n3p180

\begin{abstract}
The aim of the study was to evaluate the benefits from 4th year surgical course for medical students upon reaching 6th year surgical course. A questionnaire survey was conducted and questions regarding student satisfaction with the 4th year course and the benefits gained from this course in the 6th year were evaluated. Students were questioned regarding their interest in surgery as a career. A total of 67 students were enrolled in the study and the information collected from them was analyzed. The results showed that only 35 students reported in agreement of offering 1 surgery course; whereas, only 32 students reported in agreement of 2 surgery courses. The results also showed that only 26 students were interested in surgery as a career. The study emphasized on spreading awareness among students regarding surgery, and suggested that courses must be introduced in the curriculum to help students in their future decision making.
\end{abstract}

Keywords: surgery, medical students, medicine, university, surgical course

\section{Introduction}

The surgical courses play an important role in providing basic clinical training for the medical students. The regional campuses of the majority of the medical schools have been expanded in order to address the predicted shortage of primary care physicians. Students are expected to develop competence in correlating clinical problems with basic surgical science learned during previous years and develop a foundation in reasoning, procedural and communication skills. These skills are necessary for effective and compassionate care of adult patients with surgical disorders. Students are expected to learn how to access numerous available sources of surgical information, develop an evidence-based approach to patient care, and guide their way toward efficient use of reading time and clinical work. For instance, the students' first clinical exposure to patients with surgical diseases is represented in the fourth-year surgical course at Umm Al-Qura University's Faculty of Medicine. During the course, students check patients in both the emergency and inpatient departments to broaden their exposure and mimic the experience of a house surgeon.

Several complicated surgeries, such as, plastic surgery, kidney-transplant etc. require special skills, which cannot be learned easily without related courses and training. Moreover, the interest of students can also be explored by offering them courses, which enlighten them about the specialty of the course and related field (Khatib et al., 2015). Such courses can solve misconception of students and can also increase their awareness regarding this particular area of education. However, there has been a decline witnessed in the number of students willing to learn general surgery, accounting for a decrease in the number of efficient surgeons in the future (Avery, 2018). Therefore, it is important to focus on teaching practical skills instead of theoretical skills. The students need to enhance their skills by implementing the knowledge they learnt in the previous years (Schoeb et al., 2016).

The rate of mortality increases each year resulting from annual changeover of junior doctors, which lowers the level of efficiency of hospitals (Singh et al., 2015). Therefore, junior doctors must be equipped with sufficient surgical knowledge so that they can easily resolve severe cases. The students can enhance their expertise by participating in the surgical courses offered in their universities or other institutions (Egol et al., 2015). Surgical information can also be learned through electronic media or information technologies providing a plethora of information, which subsequently help students to gain easy access to information (Aryal \& Pereira, 2014). 
However, the supervision of teachers is also essential in enhancing the knowledge of surgical training (Aryal \& Pereira, 2014).

Considering the above-mentioned consequences, a course was developed at Umm Al-Qura University's Faculty of Medicine for establishing competency in the principles of surgery with special emphasis on gaining skills required for obtaining a comprehensive history, performing a systematic physical examination, and formulating a reasonable differential diagnosis. Moreover, most common surgical diseases in the community were used to confirm the diagnosis and interpretation of results to reach a provisional diagnosis with basic knowledge and understanding of investigations. Passing this course is a pre-requisite to advance to the 5th and then the 6th year, when they will be exposed to the surgery 3 course, which greatly depends on the basic knowledge and skills acquired in the surgery 1 course with more stress on management and treatment.

There is a critical shortage of general surgeons across the world that has threatened the hospital's survival. It is important for the students to develop the ability of self-learning and proper attitude to deal with patients by understanding the effect of surgical interventions taking into consideration the family background, socioeconomic status, and Islamic laws in planning therapy. Therefore, the present study aims to evaluate the benefits of a 4th year surgical course upon reaching the 6th year surgical course for medical students. It assesses the effectiveness of a surgical course in enhancing their practical skills with regard to surgery. Moreover, the study also evaluates the level of self-learning developed in medical students after receiving practical surgical training. The study aims to answer the following research questions:

1) Does the surgical course offered in the 4th year provide sufficiently practical knowledge to medical students in the 6th year?

2) Are the surgical courses capable of improving the level of awareness and self-learning among medical students?

\section{Literature Review}

Taylor et al. (2017) conducted a study to evaluate procedures to attract more medical students toward surgical residencies. The study highlighted that the number of medical students interested in general surgery has been decreasing significantly which accounts for the decline of residents in general surgery. On the other hand, interaction with faculty, operative experience and mentoring opportunities were found to be the reasons why students opt for general surgery. An evaluation of general surgery clerkship was carried out to evaluate the information obtained from the two-month long clerkship of students. The results of the study showed that students were highly satisfied with the level of responsiveness they received from the faculty and also showed strong satisfaction towards operative experience. However, the study did not show any observation regarding the performance of students during clerkship or regarding the organization of lectures. Such that, the study suggested that responses of students must also be incorporated into organizations to increase their association. Therefore, such initiatives can significantly enhance the interest of students into residency positions.

Another study conducted by Matlok et al. (2015) evaluated the knowledge of Polish medical students regarding surgical treatment of obesity. The problems related to obesity have become a topic of concern; therefore, practitioners are required to gain significant knowledge regarding the surgical treatment of obesity. However, the knowledge of surgical treatments of obesity among medical practitioners is less than moderate. To this end, the study was aimed to evaluate the knowledge of surgical treatments of obesity among medical students of four different universities. A total of 468 students were enrolled in the study and the data were collected through a questionnaire survey. The results of the study depicted that the students possessed insufficient levels of knowledge regarding metabolic surgery for the treatment of obesity. To this end, the study showed that there is a need to enhance the level of knowledge among medical students regarding the surgical procedures of obesity.

Antonoff et al. (2014) discussed the issues related to the surgical education of cardiothoracic surgery. The following era of surgical education is still faced with a number of challenges, to this end; the study emphasized increasing the level of knowledge among medical students. Such that, to increase knowledge among students, the study focused on developing and deploying an online learning course that highlights basic topics of cardiothoracic surgery. To evaluate the efficiency of the course, the study included 4 online self-study courses for investigation. Only 9 students opt for four online courses based on tracheal disease. On the other hand, the mean time spent by students on a course was 1.35 hours and the attempts per course were found to be 2.86 . The results depicted that online courses can be beneficial in providing additional help to the students regarding cardiothoracic surgery. Moreover, the assessments on such platforms can help students to increase their level of awareness. On the other hand, these courses are time and cost-efficient which is another benefit that can be utilized. 
Hill et al. (2014) conducted a study to determine the perceptions of surgeons and surgical careers. The applications received for surgical residencies have showed a significant decline in the past few years. The study highlighted the aspect as how students make their career decisions. A questionnaire approach was adopted in the study to collect information from students regarding their perceptions of surgery or surgeons. Moreover, interviews were also conducted to evaluate the themes, which were then analyzed to derive a conclusion. Students assumed surgeons as intimidating and self-confident, as reported by the results. On the other hand, students took surgery as sacrificing, competitive and masculine. Therefore, students assumed that they need to fit this category if they want to be surgeons, which restricted students to pursue surgery. Such that, the results reported that surgery was not a realistic or an attractive option for students.

\section{Methodology}

The study was conducted in the academic year 2015-2016 with a total of 263 students as a sample among whom 137 were males and 126 were females. The inclusion criteria for this study included all the students in the 6th year at Umm Al-Qura University's Faculty of Medicine. The questionnaire was distributed electronically to the entire batch of 6th year medical students. The ethical committee approval was taken from the concerned institute before conducting the study analysis. Moreover, each student was informed about his/her rights as a participant and a consent form was signed by each of them before recruiting them into the study.

A questionnaire survey was conducted to collect a range of information from the participants, which included questions about student satisfaction with the 4th year course, their evaluation of the course, and how much benefit they gained from the 4th year's surgical course in the 6th year surgical course. The questionnaire was based on isolating the important consequences pertaining to the research questions. For instance, the questionnaire included questions about the degree of benefit from particular components of the 4th year course, including: problem-based learning (PBL), skill lab sessions, hospital bedside teaching and lectures. Students were questioned if they would like to pursue a career in surgery. Students were also questioned if they preferred to have 2 separate surgical courses or a single course instead. The questionnaire was pre-tested among ten medical students; however, their data were not taken up for further analysis. Cronbach's alpha was used to measure reliability of the questionnaire items (Table 1). It is commonly used for questionnaires based on Likert questions to determine the scale's reliability.

Table 1. Reliability statistics

Cronbach's Alpha

0.743

Chi-square statistics have been used to determine the association between categorical variables. Paired sample t-test has been used to evaluate the difference between understanding levels of 4 th and 6 th year students. The significant results were reported at a $5 \%$ level of significance.

\section{Results}

A total of 67 students (25.5\%) responded to the questionnaire survey 36 males (53.8\%) and 31 females (46.2\%). Table 2 shows the information regarding the preference of teaching surgery to medical students as two separate courses offered in the 4 th and 6 th years.

Table 2. Data showing the importance of surgery courses for medical students

\begin{tabular}{lll}
\hline Variable & Male 36 (53.8\%) & Female 31 (46.2\%) \\
\hline Would it be better to teach surgery to medical students as 1 or 2 separate courses? & 1 course 35 (52.2\%) & 2 courses 32 (47.8\%) \\
\hline
\end{tabular}

Does the surgical course offered in the 4th year provide sufficiently practical knowledge to medical students in the 6th year?

Table 3 shows that 9 (13.4\%) students identified the current 4th year surgical course at the medical faculty of Umm Al-Qura University as poor, 25 (37.3\%) students reported it as borderline, 12 (17.9\%) as good, 18 (26.9\%) as very good, and $3(4.5 \%)$ as excellent. Moreover, regarding the benefits from the course, $9(13.4 \%)$ students reported it as poor, $15(22.4 \%)$ as borderline, $24(35.8 \%)$ as good, $15(22.4 \%)$ as very good, and $4(6 \%)$ as excellent. Regarding teaching clinical skills in simulation centers, $22(32.8 \%)$ students reported it as poor, 14 (20.9\%) students as borderline, and $19(28.4 \%)$ as good, $7(10.4 \%)$ as very good, and $5(7.5 \%)$ students reported 
it as excellent. Regarding lectures, 9 (13.4\%) students reported them as poor, $12(18 \%)$ as borderline, $16(23.9 \%)$ as good, $21(31.3 \%)$ as very good, and $9(13.4 \%)$ as excellent. Regarding clinical bedside teaching, $10(15 \%)$ students reported it as poor, $9(13.4 \%)$ as borderline, $21(31.3 \%)$ as good, $18(26.9 \%)$ as very good, and $9(13.4 \%)$ as excellent. Lastly, regarding small group teaching or problem-based learning (PBL), 28 (41.7\%) students reported it as poor, $9(13.4 \%)$ as borderline, $20(30 \%)$ as good, $6(8.9 \%)$ as very good, and $4(6 \%)$ as excellent. Moreover, the benefits of surgical courses are reported significantly based on the 4th year surgical course $(\mathrm{p}=$ $0.002)$, teaching clinical skills in the simulation center $(\mathrm{p}=0.003)$, lectures $(\mathrm{p}=0.035)$, bedside teaching $(\mathrm{p}=$ 0.018), small group teaching/problem-based learning $(\mathrm{p}=0.024)$. However, benefit from the course was insignificantly associated with the benefits of surgical courses $(\mathrm{p}=0.145)$.

Table 3. Information regarding the benefits of surgical courses

\begin{tabular}{lllllll}
\hline Variable subject to evaluation & Excellent & Very good & Good & Borderline & Poor & p-value \\
\hline 4th year surgical course & $3(4.5 \%)$ & $18(26.9 \%)$ & $12(17.9 \%)$ & $25(37.3 \%)$ & $9(13.4 \%)$ & 0.002 \\
Benefit from the course & $4(6 \%)$ & $15(22.4 \%)$ & $24(35.8 \%)$ & $15(22.4 \%)$ & $9(13.4 \%)$ & 0.145 \\
Teaching clinical skills in simulation center & $5(7.5 \%)$ & $7(10.4 \%)$ & $19(28.4 \%)$ & $14(20.9 \%)$ & $22(32.8 \%)$ & 0.003 \\
Lectures & $9(13.4 \%)$ & $21(31.3 \%)$ & $16(23.9 \%)$ & $12(18 \%)$ & $9(13.4 \%)$ & 0.035 \\
Bedside teaching & $9(13.4 \%)$ & $18(26.9 \%)$ & $21(31.3 \%)$ & $9(13.4 \%)$ & $10(15 \%)$ & 0.018 \\
Small group teaching/problem-based learning & $4(6 \%)$ & $6(8.9 \%)$ & $20(30 \%)$ & $9(13.4 \%)$ & $28(41.7 \%)$ & 0.024 \\
\hline
\end{tabular}

Table 4 shows the information regarding degree of interest of students in pursuing surgery. The results showed that $26(38.8 \%)$ students were $0-20 \%$ interested in pursuing a career in surgery as a specialty, $7(10.4 \%)$ students were $20-40 \%$ interested, $13(19.5 \%)$ students were $40-60 \%, 12(17.9 \%)$ students were $60-80 \%$ and $9(13.4 \%)$ were $80-100 \%$ interested. Finally, 35 (52.2\%) students thought that it would be better to teach surgery to medical students in 1 course instead of 2, while $32(47.8 \%)$ thought it would be better to continue to teach surgery as 2 courses. Moreover, interest of students in pursuing surgery was significantly associated with the 4th year students $(\mathrm{p}=0.015)$.

Table 4. Information regarding degree of interest of students in pursuing surgery

\begin{tabular}{lcccccr}
\hline Variables & Excellent & Very Good & Good & Borderline & Poor & P-value \\
\hline \multicolumn{2}{l}{ To what degree are you interested in pursuing a career in surgery? } & & & & \\
Number of students & $26(38.8 \%)$ & $7(10.4 \%)$ & $13(19.5 \%)$ & $12(17.9 \%)$ & $9(13.4 \%)$ & 0.015 \\
\hline
\end{tabular}

The study has examined gender-wise marks as a comparison between 4th year and 6th year classes. As per the findings, the study has reported that $94.3 \%$ of 4 th year female students have achieved more than 70 marks (out of a 100$)$ in their surgery course as compared to 6th year female students $(83.7 \%)$. Similarly, $78.9 \%$ of 4 th year male students have achieved more than 70 marks in their surgery course as compared to 6th year male students in their surgery course. Comparatively, the ratio of achieving less than 70 marks was reported among 6th year students (both male and female) as compared to their counterparts (Table 5).

Table 5. Comparison between 4th year and 6th year students' marks in surgery courses

\begin{tabular}{|c|c|c|c|c|c|c|c|c|}
\hline & \multicolumn{8}{|c|}{ Class } \\
\hline & \multicolumn{2}{|c|}{ 4th Year (Female) } & \multicolumn{2}{|c|}{ 4th Year (Male) } & \multicolumn{2}{|c|}{ 6th year (Female) } & \multicolumn{2}{|c|}{ 6th Year (Male) } \\
\hline & $\mathrm{N}$ & $\%$ & $\mathrm{~N}$ & $\%$ & $\mathrm{~N}$ & $\%$ & $\mathrm{~N}$ & $\%$ \\
\hline$<70$ marks & 5 & 4.1 & 26 & 21.1 & 18 & 14.6 & 55 & 44.7 \\
\hline$\geq 70$ marks & 116 & 94.3 & 97 & 78.9 & 103 & 83.7 & 68 & 55.3 \\
\hline Total & 121 & 100 & 123 & 100 & 121 & 100 & 123 & 100 \\
\hline
\end{tabular}

Are the surgical courses capable of improving the levels of awareness and self-learning among medical students?

The study has examined the understanding level towards surgery between 4th and 6th year students through paired sample t-tests. The findings have reported that there is a significant difference between the understanding levels of students of both classes. This indicates that the understanding level of 6th year students will be much better as compared to students of the 4th year due to difference in comprehension, awareness, potential to grasp 
knowledge, and syllabus being taught (Table 6).

Table 6. Difference between the understanding level of 4th year and 6th year students

\begin{tabular}{|c|c|c|c|c|c|c|c|c|c|}
\hline & & \multicolumn{5}{|c|}{ Paired Differences } & \multirow[t]{3}{*}{$\mathrm{t}$} & \multirow[t]{3}{*}{ df } & \multirow{3}{*}{$\begin{array}{l}\text { Sig. } \\
\text { (2-tailed) }\end{array}$} \\
\hline & & \multirow[t]{2}{*}{ Mean } & \multirow[t]{2}{*}{$\begin{array}{l}\text { Std. } \\
\text { Deviation }\end{array}$} & \multirow[t]{2}{*}{$\begin{array}{l}\text { Std. Error } \\
\text { Mean }\end{array}$} & \multicolumn{2}{|c|}{$\begin{array}{l}95 \% \text { Confidence Interval } \\
\text { of the Difference }\end{array}$} & & & \\
\hline & & & & & Lower & Upper & & & \\
\hline Pair 1 & $\begin{array}{l}4 \text { th year female - } \\
6 \text { th year female }\end{array}$ & 4.10744 & 4.64364 & .42215 & 3.27161 & 4.94326 & 9.730 & 120 & .000 \\
\hline Pair 2 & $\begin{array}{l}\text { 4th year male - } \\
6 \text { th year male }\end{array}$ & 6.35772 & 4.97556 & .44863 & 5.46961 & 7.24583 & 14.171 & 122 & .000 \\
\hline
\end{tabular}

\section{Discussion}

The results of the study showed that 35 students agreed that only one surgery course must be taught; however, 32 students showed that two courses must be taught to enhance knowledge regarding surgery. Students reported over all good benefits of the course with 21 students reporting the significance of lectures. 28 students reported poor response regarding small group teaching. On the other hand, only 26 out of 67 students showed interest in pursuing surgery as a career. To this end, the results put emphasis on the notion to evaluate factors which influence the career decisions of students.

The study conducted by Kumar et al. (2014) showed that a large number of students were interested in adopting surgery in the future. The results were inconsistent with the findings of the study in which less than $50 \%$ of students were interested in surgery. The study was conducted in China, Malaysia and other regions of SAARC. The results depicted that Biochemistry, physiology and anatomy were the most preferred subjects by the students. Moreover, internal medicine, surgery and pediatrics were found to be the preferred career choices of students. The results showed that males were significantly interested in adopting surgery; whereas, their female counterparts were more interested in gynecology and obstetrics. The study results also depicted that the choices of students were significantly influenced by leading a good quality of life. Therefore, students mostly preferred to opt for specialties that met such demands.

Dolan-Evans and Rogers (2014) also reported results that were found to be consistent with the results of the following study. The results depicted insignificant results between the choices of students while opting for a surgical career. The results indicated a decline in the surgical interest of students from the 1st year to the 2nd year. Moreover, training length, lifestyle and working hours had no significant influence on the decision of students. Based on findings, the study recommended that students must be encouraged and motivated to opt for surgery as their specialization by acknowledging them regarding the scientific and academic aspect of surgery.

Regarding the understanding level of students, the study has reported a significant difference between the understanding level of 4th year and 6th year students. This finding has been consistently supported with the findings of previous studies. For instance, Burgos and Josephson (2014) have reported that female students are more likely to be discouraged to study surgery due to lack of female role models in this particular field.

The study conducted by Minter et al. (2015) also discussed the transition to surgical residency. The results of the study depicted that selected interns were only half prepared for the care responsibilities in the surgical ward. However, the participants reported that they were sufficiently ready for system-based practice domains, professionalism, practice-based learning, and interpersonal communication. Despite of the positive attitude of participants, the study emphasized on the programs to increase the level of prepareness among participants. However, male students are more prone towards becoming surgeons as compared to their counterparts. Duarte et al (2016) have reported that female students achieve higher scores as compared to their male counterparts towards medical courses. This finding has been consistent with the findings of the current study that female students in both 4th and 6th year surgery course achieve higher marks as compared to their male counterparts.

Several limitations have been reported despite of the significant results. The sample size is very small with regard to the information collected in the study. By considering a larger sample size, more generalized results can be produced. On the other hand, the study did not conduct any tests to evaluate the factors that influenced the choice of students while selecting surgery as a career. By determining the factors influencing the choice of students, relevant strategies can be developed that can help in raising awareness among students. Moreover, no particular strategy was discussed in the study to acknowledge students about the future benefits of adopting 
surgery as an area of specialization. Moreover, the study results are limited due to inadequate time of distributing the questionnaire, when some of the students were busy that may lead to lack of concentration while answering the questions.

The results of this study are significant as it clearly depicts the shift from the classical form of knowledge through teacher centered education towards practical skills that are necessary for real-life medical practice. It is highly imperative to implement the new teaching methods in the curricula of the medical school. The study clarifies the significance of a surgical course for medical students, where practical and theoretical knowledge would be taught to them through practicing of the real surgical procedures on anatomical specimens.

To this end, surgical knowledge is necessary for the students to increase awareness among students regarding this area of specialization. The sudden decline from medical students towards surgery has attracted the attention of a number of researchers. Without students adopting surgery as their area of specialization, there will be a dearth of surgeons in the hospitals. Therefore, the study has highlighted the importance of teaching surgery courses in the 4th year and its benefits for medical students in their 6th year. The study also demonstrated the interest of students towards adopting surgery as their career; also, factors which influenced the career decisions of students were discussed. The results showed that less than $50 \%$ of the sample was interested in adopting surgery as their career. Also, the students showed varying results regarding the benefits of teaching surgery as a course in the 4th year compared to a surgery course taught in 6th year. The future studies need to assess the confidence level of students regarding their practical skills and how to improve their attitude towards the patient related tasks.

\section{Acknowledgements}

The author is very thankful to all the associated personnel in any reference that contributed in/for the purpose of this research. Further, this research holds no conflict of interest and is not funded through any source.

\section{References}

Antonoff, M. B., Verrier, E. D., Yang, S. C., Lin, J., DeArmond, D. T., Allen, M. S., \& Vaporciyan, A. A. (2014). Online learning in thoracic surgical training: promising results of multi-institutional pilot study. The Annals of Thoracic Surgery, 98, 1057-1063. https://doi.org/10.1016/j.athoracsur.2014.04.062

Aryal, K. R., \& Pereira, J. (2014). E learning in surgery. Indian Journal of Surgery, 76, $487-493$. https://doi.org/10.1007/s12262-014-1092-8

Avery, D. (2018). Do Regional Medical Campuses Contribute to the Production of General Surgeons? A Study of 789 Medical School Graduates from 3 Campuses Who Matched into General Surgery Residencies over 40 Years: 1974 to 2015. Journal of Regional Medical Campuses, 1. https://doi.org/10.24926/jrmc.v1i2.1283

Burgos, C. M., \& Josephson, A. (2014). Gender differences in the learning and teaching of surgery: a literature review. International Journal of Medical Education, 5, 110. https://doi.org/10.5116/ijme.5380.ca6b

Dolan-Evans, E., \& Rogers, G. D. (2014). Barriers for students pursuing a surgical career and where the Surgical Interest Association can intervene. ANZ Journal of Surgery, 84, 406-411. https://doi.org/10.1111/ans.12521

Duarte, M. I. F., Raposo, M. L. B., da Silva Farinha, P. J. F., \& Branco, M. C. (2016). Measuring empathy in medical students, gender differences and level of medical education: An identification of a taxonomy of students. Investigación en Educación Médica, 5(20), 253-260. https://doi.org/10.1016/j.riem.2016.04.007

Egol, K. A., Phillips, D., Vongbandith, T., Szyld, D., \& Strauss, E. J. (2015). Do orthopaedic fracture skills courses improve resident performance? Injury, 46, 547-551. https://doi.org/10.1016/j.injury.2014.10.061

Hill, E. J., Bowman, K. A., Stalmeijer, R. E., Solomon, Y., \& Dornan, T. (2014). Can I cut it? Medical students' perceptions of surgeons and surgical careers. The American Journal of Surgery, 208, 860-867. https://doi.org/10.1016/j.amjsurg.2014.04.016

Khatib, M., Soukup, B., Boughton, O., Amin, K., Davis, C. R., \& Evans, D. M. (2015). Plastic surgery undergraduate training: how a single local event can inspire and educate medical students. Annals of Plastic Surgery, 75, 208-212. https://doi.org/10.1097/sap.0000000000000058

Kumar, A., Mitra, K., Nagarajan, S., \& Poudel, B. (2014). Factors influencing medical students' choice of future specialization in medical sciences: a cross-sectional questionnaire survey from medical schools in China, Malaysia and regions of South Asian association for regional cooperation. North American Journal of Medical Sciences, 6, 119. https://doi.org/10.4103/1947-2714.128473

Matłok, M., Pędziwiatr, M., Major, P., Nowakowski, M., Rubinkiewicz, M., Wyleżoł, M., \& Budzyński, A. 
(2015). The knowledge of Polish medical students about surgical treatment of obesity. European Surgery, 47, 266-270. https://doi.org/10.1007/s10353-015-0331-y

Minter, R. M., Amos, K. D., Bentz, M. L., Blair, P. G., Brandt, C., D'cunha, J., \& Kingsley, D. (2015). Transition to surgical residency: a multi-institutional study of perceived intern preparedness and the effect of a formal residency preparatory course in the fourth year of medical school. Academic Medicine, 90, 1116-1124. https://doi.org/10.1097/ACM.0000000000000680

Schoeb, D. S., Brennecke, E., Andert, A., Grommes, J., von Trotha, K. T., Prescher, A., \& Binnebösel, M. (2016). Assessment of a course of realistic surgical training during medical education as a tool for pre-residential surgical training. BMC Medical Education, 16, 45. https://doi.org/10.1186/s12909-016-0568-6

Singh, P., Aggarwal, R., Pucher, P. H., \& Darzi, A. (2015). Development, organisation and implementation of a surgical skills 'Boot Camp': SIMweek. World Journal of Surgery, 39, 1649-1660. https://doi.org/10.1186/s12909-016-0568-6

Taylor, G., Wallace, J. C., Harrell, A. G., Burkhardt, J., Avery, D. M. Jr., \& Geno, C. E. (2017). How Can We Attract More Medical Students to General Surgery Residencies? A Study of Medical Student Evaluations of a General Surgery Clerkship for 10 Years: 2005-2015. Clin Surg, 2, 1722.

\section{Copyrights}

Copyright for this article is retained by the author, with first publication rights granted to the journal.

This is an open-access article distributed under the terms and conditions of the Creative Commons Attribution license (http://creativecommons.org/licenses/by/4.0/). 